\title{
Towards more effective strategies for management of diabetes in Mauritius
}

\author{
Hemant Kassean \\ University of Mauritius, Reduit, Mauritius; h.kassean@uom.ac.mu \\ Received 20 January 2012; revised 23 February 2012; accepted 6 March 2012
}

\section{ABSTRACT}

Over the past 2 decades, the prevalence of diabetes in Mauritius has remained one of the highest in the world with no recent significant improvement. Mauritius ranked $2^{\text {nd }}$ in 2002 and $4^{\text {th }}$ in the world in 2009 with nearly one in five of its adult population above the age of 30 years being affected. Nearly half of those affected do not know that they have the disease and this adversely influences quality of life, risks of complications as well as morbidity and mortality. Despite the availability of free health services, over $50 \%$ of diabetes patients are poorly controlled and the risk of complications from diabetes such as cardiovascular diseases, renal failure, blindness, peripheral vascular and neurological diseases leading to lower limb amputations, remain very high. Despite continued efforts from the Ministry of Health and Quality of Life (MOH \& QOL) to provide easily accessible diabetes care to all patients, the outcome remains poor. Most of the outpatients and primary health care centres are overcrowded and the set-up does not provide optimal care and attention. Diabetes care is very much medical-orientated and the health promotion campaigns have had little impact so far. Prevention and control of diabetes must become a priority. There is an urgent need for enhanced heath promotion and education, as evidence suggests that a change in diet and lifestyle can bring about significant improvement in the incidence and prevalence of diabetes. This paper examines some of the key actions/ proposals with respect to: evaluation of actions taken, health promotion campaigns, attitude and behavioural change, focused leadership and commitment, marketing strategies, effective segmentation and targeting.

Keywords: Diabetes; High Prevalence; Mauritius; Prevention; Health Promotion

\section{INTRODUCTION}

The objective of this paper is to examine the actions taken with respect to diabetes prevention and health promotion campaigns in Mauritius and discuss strategies in terms of evaluation of actions/health promotion campaigns, attitude and behavioural change, leadership and commitment, marketing strategies, effective segmentation and targeting.

Diabetes mellitus can be found in almost every population in the world and epidemiological evidence suggests that, without effective prevention and control programmes, diabetes will likely continue to increase globally [1]. Diabetes mellitus (DM) is now one of the most common non-communicable disease globally. It is the fourth or fifth leading cause of death in most high-income countries and there is substantial evidence that it is epidemic in many economically developing and newly industrialized nations [2]. Complications from diabetes, such as coronary artery and peripheral vascular disease, stroke, diabetic neuropathy, amputations, renal failure and blindness are resulting in increasing disability, reduced life expectancy and enormous health costs for virtually every society. Diabetes is undoubtedly one of the most challenging health problems in the 21 st century. It is now recognized that it is the low-and middle income countries (LMCs) that face the greatest burden of diabetes [3]. However, many governments and public health planners still remain largely unaware of the current magnitude, or, more importantly, the future potential for increases in diabetes and its serious complications in their own countries $[2,4]$.

\subsection{Top 10 Prevalence of Diabetes in the World}

Top 10: Prevalence (\%) of diabetes (20 - 79 years), 2009.

As shown in Table 1, Nauru has the highest prevalence of diabetes in the world with $30.9 \%$ of the population being affected [2]. Mauritius is $4^{\text {th }}$ with $16.2 \%$ after the United Arab Emirates and Saudi Arabia. This figure however, was found to be much higher [2]. In 2002, 
Mauritius ranked $2^{\text {nd }}$ in terms of prevalence of diabetes in the world [6] and in 2009, it ranked $2^{\text {nd }}$ again [5] with a figure of $21.3 \%$ instead of $16.2 \%$ as shown in the Table 2 below.

\subsection{Trend in the Prevalence of Diabetes 1987-2009}

Table 2 shows the trend in the prevalence of diabetes in Mauritius between 1987-2009. The survey results show that the prevalence of diabetes has been constantly on the increase from 14.3 in 1987 to 21.3 in 2009, except for the period 1998-2004 where there was a slight decrease from 19.5 to 19.3 [2].

Despite the health promotion campaigns since 1987, the rate remains alarmingly high and from this trend, it can be deduced that the prevalence of diabetes in Mauritius will probably continue to stay high for years to come and radical actions are needed urgently in order to take preventive measures and reduce the risk factors. Evidence suggests that a healthy diet and exercise can contribute significantly to this cause $[2,7]$.

\subsection{Prevalence of Diabetes in Mauritius}

The Non Communicable Disease, NCD survey [5] in Mauritius, has shown that the prevalence diabetes was $21.3 \%$, among Mauritians, the majority of which (about

Table 1. Source IDF diabetes atlas 4th Ed. [2].

\begin{tabular}{lc}
\hline \multicolumn{1}{c}{ Country/Territory } & 2009 Prevalence (\%) \\
\hline 1) Nauru & 30.9 \\
2) United Arab Emirates & 18.7 \\
3) Saudi Arabia & 16.8 \\
4) Mauritius ${ }^{*}$ & 16.2 \\
5) Bahrain & 15.4 \\
6) Reunion & 15.3 \\
7) Kuwait & 14.6 \\
8) Oman & 13.4 \\
9) Tonga & 13.4 \\
10) Malaysia & 11.6 \\
\hline
\end{tabular}

*Contrast with [5] Mauritius findings: 21.3\%.

Table 2. Prevalence of diabetes from 1987 to 2009.

\begin{tabular}{cccccc}
\hline & 1987 & 1992 & 1998 & 2004 & 2009 \\
\hline Male & 14.2 & 16.3 & 18.4 & 18.9 & 21.9 \\
Female & 14.5 & 17.4 & 20.6 & 19.7 & 20.6 \\
Total & 14.3 & 16.9 & 19.5 & 19.3 & 21.3 \\
\hline
\end{tabular}

Source: NCD surveys.
$99 \%$ ) were type 2 diabetes. The reason for this high rate of diabetes in Mauritius could be explained by a combination of risk factors such as physical inactivity, unhealthy diet and overweight, high prevalence of smoking and genetic background of the population. The rapid economic development the country experienced during the mid-eighties has also led to changes in the lifestyle of the population. Most of the people with diabetes have poor control of their condition and consequently suffer from many of the complications of diabetes such as cardiovascular diseases, kidney failure, blindness, damaged nerves to limbs and amputations secondary to peripheral vascular disease [5]. At present diabetes prevalence remains high in Mauritius and will probably continue to stay high for many years to come. There may be as many as 120,000 diabetics with nearly $50 \%$ of them not knowing that they have the disease [8].

\subsection{Costs of Diabetes}

There are not many studies which have investigated the cost of diabetes in the region. It estimated that the total economic cost (direct and indirect) of diabetes in the WHO's Africa region in 2000 was Int $\$ 25.51$ billion (US $\$ 67.03$ billion), or Int $\$ 3363$ (US $\$ 8836$ ) per person with diabetes per year (numbers converted from International dollars to their equivalent value in US dollars [9]. The direct cost of treating diabetes in 2000 ranged from Int $\$ 876$ (US \$2302) to Int $\$ 1220.6$ (US \$3207) per person [9]. The burden of the disease in terms of costs is enormous. According to the National Service Framework for Diabetes [8], more than one in five deaths are caused by diabetes. Some of its costs are:

- Direct cost - to people with diabetes in terms of productivity

- Direct cost- to healthcare system in terms of care and treatment

- Indirect cost to society-impact on family and society as a whole.

\section{EVALUATION OF ACTIONS TAKEN/HEALTH PROMOTION CAMPAIGNS}

The prevalence of diabetes has increased by over $60 \%$ since 1987 in adult Mauritian population aged $25-74$ years [5]. This alarmingly high prevalence rate of diabetes in Mauritius over the past 24 years clearly indicate that actions taken by the health authority to prevent its incidence has remained largely unsuccessful. There has been an absence of a coherent National Diabetes Prevention Strategy with a clear action plan to achieve specific measurable outcomes. Some of the actions taken are discussed in this section:

Screening Programmes: In all the 26 Area Health 
Centres in Mauritius, people are screened for diabetes during one session every week on appointment. During these sessions the following tests are done: BMI (Body mass Index), Blood pressure, Blood sugar [10].

Although this is a useful service, it caters mostly for people who come for this screening when they experience complications of diabetes. At this stage, the condition has already progressed with a high level of morbidity and enormous cost to the health sector.

Caravane de la Sante: Since 2001, screening services are also offered by the Caravane de la Sante which goes to the workplace and into the community. This service has been extended to tertiary education institutions in 2006 and secondary schools in 2007 [10].

Although this action goes some way towards detecting the condition early, it is important that all the citizens of Mauritius are sensitised to this problem and take a personal and active role in monitoring their diabetic status and health in general.

Treatment: Among those people known to have diabetes, control of their diabetes as judged by blood glucose levels was poor $(47 \%$ had $\mathrm{HbAlc} \geq 9.0 \%)$, indicating very high risk of developing diabetic complications [11].

Treatment of diabetes is available in all the Community Health Centres, Area Health Centres and Regional Hospitals, Complications are followed up in the regional hospitals and in specialized hospitals such as the Subramanya Bharati Eye Hospital and the Cardiac Centre. Each regional hospital has a renal dialysis unit which is under the care of the medical unit and it caters for all the patients needing haemodialysis of the region [12].

With a large level of people suffering from chronic problems associated with diabetes, the treatment centres are always overcrowded and treatment tends to be mostly pharmacological [13]. There is also a large percentage of diabetics who are not capable of following the strict regime required to bring their diabetes under control due to a whole host of reasons: health illiteracy, visual impairment, various other complications and general ill health. The above study also found that there are no diabetic specialist nurses/clinical specialist to follow the individual cases and most of them tend to get a standard treatment. Often, their next appointment is in 6 months time, by which time the patient's conditions have worsened. Often, also their tests results cannot be located as these are not logged on to a database system.

\section{Diabetes Awareness/Sensitisation Programmes}

World Diabetes Day, 14 November 2006. World Diabetes Day in Mauritius was commemorated with the launching of this website and an exposition with the theme "Diabetes care for everyone" at Gymkhana Club, Vacoas by the Minister of Health \& Quality of Life on Sunday, 12 November 2006 [14].

Television Programme, 15 November 2006. A special programme on "Diabetes Care and Complications" will be aired on Wednesday 15 November 2006 at 20:30 pm on MBC TV channel 1. A panel of doctors in different fields will put special emphasis on the importance of diabetes care and its relation to complications [14].

These types of programmes are very useful in reaching out to the people they do not happen regularly basis and no assessment and monitoring is done on lifestyle change following these programmes and other preventive actions. Each Mauritian should have a secure health smart card which provides up to date information on the health status of the individual. These records should also be available through a secure database system. This would resolve the problem of loss of test results and also duplication of tests, allowing the health system to make savings and more importantly enable the health practitioner to make swift decisions [15].

\section{Brochures and Posters}

One of the promotional campaign launched by the Ministry of Health and Quality of Life involves the distribution of posters and brochures. Several types of posters have been displayed in primary, secondary schools, social centers, hospitals and dispensaries, and other public buildings. The aim behind these posters is to educate the Mauritian population and raise awareness on the importance of getting their diabetic status checked [16].

Besides in English and French, these should be published in other local languages e.g. creole, Bhojpuri in simple layman's term that touches people in a special way eg "This is about you — when did you have your last blood test for diabetes" so that it attracts peoples' attention and spur them to action [17].

\section{THERAPEUTIC LIFESTYLE CHANGE: A ROAD TO PREVENTION}

With the growing epidemic of diabetes, it is important that we continue to intensify research in this area in order to prevent or delay the onset of type 2 diabetes. Data from randomized controlled trials $[18,19]$ have shown that interventions to promote therapeutic lifestyle change (TLC), like healthy food intake, weight reduction, exercise promotion, and ongoing contact with a lifestyle coach positively affected the incidence of type 2 diabetes. The above studies lend support to the strength of TLC interventions by showing a respective $42 \%$ and $58 \%$ reduction in the development of type 2 diabetes.

Data from the Diabetes Prevention Program Research Group [20,21] found that TLC activities (up to $7 \%$ weight loss and 150 minutes of physical activity per week) are more effective than standard or pharmacologic therapy in preventing the onset of type 2 diabetes. Evidence from the Diabetes Prevention Program clearly shows that the onset of diabetes can be reduced or pre- 
vented, at least in the short term, with TLC. This translates into hope for people who are at risk. However, transferring comprehensive research strategies into the real world setting remains a challenge. Time constraints tend to limit the interaction between the client and the health care professional. Moreover, health care professsionals are more inclined to teach and give a brief prescription for behaviour change in an authoritative voice rather than to strategize and partner with the client on how best to begin TLC. The old way of telling the client that diabetes can lead to complications and to simply lose weight and exercise to maintain health is usually an ineffective approach. In fact, this strategy may create resistance, as it undermines the principles of autonomy, collaboration, and empowerment.

\subsection{Attitude and Behavioural Change}

People have their own set of beliefs, motives, values for learning [22]. These predispositions heavily influence the lifestyle of individuals. Once people adopt a certain lifestyle, habits settle in. Mauritians may claim to be health conscious, but in reality, a significant proportion do not seem to care much for a balanced diet, proper regular exercises and preventive measures. When they are used to a certain diet and lifestyle, most people strongly resist change, even in dramatic and serious cases [23]. The situation is similar in Mauritius as there has been little change in the general attitude of patients towards diabetes and its harmful effects over the years. Poor eating habits, like fast foods like McDonalds, fried noodles, rice and pastries especially among the young which is worrying. Thus, the promotional campaign to reduce and prevent diabetes in Mauritius has had little impact. Therefore, more radical approaches need to be adopted to deal with this epidemic.

\subsection{Understanding the Complex Nature of III Health}

It is important for those involved in health promotion to give some consideration to the concept of health itself [24]. What exactly do we mean by "health"? Strategies for health improvement require an understanding of the values and priorities in terms of working in partnership, involving communities, tackling social exclusion and inequalities. This requires taking a broader view of health and how to create a healthy society. There are many ways in which the concept of health can be understood. The traditional view is predominantly medical orientated, however as individuals, we do not think of our own health simply in terms of the presence or absence of physical symptoms. Our mental, emotional or social health can be equally important to us. Knowledge, attitude and behaviour surveys (KAB) can be useful to es- tablish peoples' knowledge of diabetes and therefore tailor the health promotion campaigns accordingly [25].

\subsection{Focused Leadership and Commitment}

The importance of political commitment from government (e.g. from the Prime Minister, and/or high ranking officers within ministries of health, education and/or sports) is crucial, as it may facilitate physical activity promotion and adoption of a healthy diet on the political agenda, particularly if the commitment is officially announced to the public [26]. Leadership is vital among key individuals involved in the implementation of a strategic plan and may come from individuals within leading agencies (e.g. high ranking officers in ministries) as well as from local programme coordinators in the intervention settings, including community, workplace and schools [26]. Leadership tasks may involve: setting up organizational structures; staff development with relevant skills, with the aim to establish a trained workforce on physical activity needs; managing communications with and information from other stakeholders; and motivating and rewarding local initiatives for their achievements. A review of urban planning/town planning and environmental policies (national and local level) is important to ensure that walking, cycling and other forms of physical activity are accessible and safe [11].

\subsection{Marketing Strategies}

Bringing about an evidence-based approach to health care, the products (and to some extent their promotion) include such initiatives as a patient information leaflet, a page on the Internet, a CD-ROM, an audit report, national guidelines, a workshop to learn critical appraisal skills [27].

It has been argued [28] that in order to bring about adoption, products need to:

- Be able to be tried without great cost or effort. It is important therefore to have them available in easily accessible places, within working hours, at times when they may be most salient, etc.

- Deliver a relative advantage. An advantage in improved patient care is something which is of the essence in both clinical audit and the clinical effectiveness programme, but needs to be shown clearly.

- Be able to be reinvented. Although this will not be a feature of all products, it is in line with the additional success that is sometimes achieved by the local adaptation of guidelines.

\subsection{Psychological Models of Change Can Help Practitioners Plan Interventions}

These models can help practitioners decide appropri- 
ate interventions which take account of individuals' attitudes towards health issues and their own health. Psychological models focus on individual decision making but the complexity making of health choices and the ways in which they may be constrained by social factors must also be taken into account. The Health Belief Model is frequently used to explain people's health actions. People's behaviour is related to their perceptions of the severity of an illness their susceptibility to it the costs and benefits of following a particular course of action [29,30]. Behaviour may also depend on a trigger, such as a symptom of ill health, the illness of a family member or a friend or a doctor's advice. The premise of the Health Belief Model is that people are basically rational. However, we must also bear in mind that people may be fearful or in denial and may not always take logical decisions about their own health-related behaviour.

\subsection{Use of Media}

In order to reach the general population, mass communication methods, such as TV, radio, newspapers and magazines, billboards and leaflets have been mainly used in Mauritius for health promotion in diabetes [31]. Wide dissemination of the national action plan and the associated programmes and strategies is necessary to reach and promote physical activity and healthy diet in a large proportion of the population. However, it has been difficult to evaluate the cost effectiveness of such approaches in diabetes prevention. It is certainly true that in some cases the use of the mass media may be less effective than face-to-face methods of addressing target groups. Yet radio, television, newspapers and magazines, and billboard posters are important sources of health information. Not everyone can be reached through community approaches and high-profile communication can reach hidden groups in the general population. The strength of the mass media lies in helping to put issues on the public agenda, in reinforcing local efforts, in raising consciousness about health issues and in conveying simple information [32]. The limitations of the mass media are that they are less effective in conveying complex information, in teaching skills, in shifting attitudes and beliefs, and in changing behaviour in the absence of other enabling factors. These however, have not been done on a regular basis and the impact of such campaigns has not been measured so far.

Other examples of dissemination that can be used include [32]:

Health exercise ambassadors where famous local athletes can be invited to promote the Healthy Exercise for All Campaign;

Youth Clubs can disseminate physical activity posters and education newsletters (clubs promoting health and well-being among the youth);

Another example of "Learn to Live Longer Campaign in Pakistan" involved a twice-daily television program of 4 - 5 minutes duration promoting participation in regular physical activity. The program was aired during prime time, on five successive days for a total duration of three months - these types of targeted approaches can be adopted in our context as well to raise awareness of this epidemic.

\subsection{Effective Segmentation and Targeting}

A national action plan should include large-scale interventions to reach the whole population and enhance physical activity and healthy eating habits at population level. Some interventions (e.g. exercise programmes, educational counselling, cooking classes) may be tailored to specific population groups, such as adults, children, older persons, employees, people with disabilities, women, men, cultural groups, people at risk to develop noncommunicable diseases. A useful approach would be to undertake demographic segmentation based on age, education level, income level, occupation, religion, life-style and media consumption habits and to tailor the specific information accordingly [33]. It is therefore important to segment the whole market because of these different characteristics and that there will be different ways in reaching these segments. A formal procedure should be used to identify the major segments, which will start by defining the bases of segmenting the market. The main reason to use this variable is that each of these segments identified have different media consumption habits. Thus, there will be different media vehicles used to reach the segments. An example of tailored exercise programmes for specific population groups include: Exercise activities at workplaces. An initiative in Thailand that is supported by national and local governments, where a number of private sector companies and state enterprises provide their employees with training and time to engage in various types of physical activities.

\subsection{Social Support for Health/Public Relations}

Getting the right person to promote the product is an essential part of marketing and of health promotion and this will usually be someone who is respected or in authority, eg opinion leaders, product champions, Community Leaders, Social, Religious Bodies, Socio-Cultural Organisations, Women Associations [34]. Social mobilezation is a pre-requisite for a successful campaign against Diabetes: all key stakeholders including social institutions, voluntary organizations, religious bodies, parent-teachers association, political leaders, representa- 
tives of municipalities, nutritionists, physical instructors, among others should all be involved in the campaign. For instance, in the different social centres of Mauritius, regular meetings can be held with the local people to raise their awareness about the alarming state of diabetes. This should be on an ongoing basis, particularly with the help of more professionals, who can be of great support and assistance to those exposed to the disease. Courses on healthy cooking can also provided in social centres.

\subsection{Creating "Health Literacy"-A Reorientation towards Prevention}

The old adage, "prevention is better than cure" is extremely relevant in this context. Health literacy is defined as the "degree to which individuals have the capacity to obtain, process, and understand basic health information and services needed to make appropriate health decisions, P16" [35]. Individuals with low health literacy may not be able to make the necessary decisions regarding their health or may not be able to adhere to maintenance guidelines as prescribed by their physicians. This can affect health care in a variety of ways. We should inculcate a culture of a well balanced diet, regular exercise and healthy activities in our young generation [36]. The ministry of education and sports can play a significant role in this context. They can launch massive prevention and sensitization campaign in schools (primary as well as secondary). The main objective of such campaign would be to inculcate the value and importance of keeping fit and having a well balanced diet. These activities should not be restricted to primary students, but it should follow in the secondary schools with regular talks by nutritionists and specialist health care professionals. An interacttive web site, with relevant and important information about diabetes could be displayed for the population at large.

\subsection{Leisure Physical Activity}

Leisure and physical activity has continued to increase steadily in both males and females during the period 1987 to 2004 [37]. The prevalence of adequate moderate or heavy leisure physical activity has increased from $11.8 \%$ in 1987 in males to $24.5 \%$ in 2004 among males and from $1.4 \%$ in 1987 to $9.5 \%$ in 2004 among females. These figures are still low, especially in females and they are likely to increase as more and more adults adopt a healthier lifestyle where regular physical activity is an important component. National guidelines or recommendations on physical activity for the general population or specific population groups (e.g. children, adolescents, adults, and older people) are important to educate the population on the frequency, duration, intensity and types of physical activity necessary for health.

\subsection{Quality Promotion through Informatics}

Computer technology and communication systems can be used to retrieve, exchange, and optimize use of biomedical information and data for making health-care decisions and solving problems [38]. Computer order entry, on-line decision support, and immediate feedback about treatment decisions can provide opportunities for improving health care. With the advent of integrated systems, data repositories, and robust analytic tools, electronic surveillance and related adverse health events can be closely monitored. A data base of individual patient's records can be created which would be easily accessible allowing health care professionals to make quicker informed decisions.

\subsection{Monitoring and Evaluation}

Evaluation and on-going monitoring of the process and outcomes of actions for the promotion of physical activity and healthy diet is necessary in order to examine programme success and to identify target areas for future plan of action [39]. Research should be capable of revealing not only whether or not a campaign has succeeded, but why [40]. Outcome evaluation may occur through national surveys and monitoring systems by including standardized measures of physical activity. Process evaluation records the implementation and may include documentation of types of programmes and actions, for example: mass media dissemination of educational materials to schools/worksites, provision of local physical activity programmes, provision of training sessions according to tailored needs of the various segments of the population. This may be done objectively in terms of the extent to which the campaign was aired number of TV spots, broadcasting times, frequency and duration, audience figures, numbers of posters and leaflets displayed). Or it may be done subjectively (TV spots seen, time spent watching, time spent reflecting, level of interest). In this sense, process evaluation more closely resembles audit. There is also a need for more sophisticated process evaluation, which would shed light on how and why an intervention has succeeded or failed to achieve its goals. Outcome evaluation focuses on the extent to which the goals of a particular programme have been met, where as process evaluation is needed to provide insights into what factors may help or hinder their achievement [41].

\section{CONCLUSION}

The focus of health promotion campaign should be in prevention of diabetes and should start with our youths so that they grow into healthier adults. This would have a multiplier effect as these youngsters are likely to influ- 
ence their parents, families and friends in adopting a healthy lifestyle. A holistic approach with combinations of different actions and programmes can be used in different settings to reach and target populations with specific and realistic outcome indicators. Possible strategies include: communitywide mass media campaigns to raise awareness on the importance and benefits of healthy diet and physical activity in the whole population and disseminate messages promoting physical activity; enhanced access to places for physical activity, i.e. provision of local play facilities for children, building walking trails; transport to work (cycling and walking) strategies for the working population; provide advice or counsel in primary care to reach older persons; formation of social networks that encourage physical activity and healthy diet. The evaluation of the action programmes should coordinated and feedback into a system so that the level of progress made is clearly visible.

\section{REFERENCES}

[1] Shaw, J.E., Zimmet, P.Z., de Courten, M., et al. (1999) Impaired fasting glucose or impaired glucose tolerance. What best predicts future diabetes in Mauritius? Diabetes Care, 22, 399-402. doi:10.2337/diacare.22.3.399

[2] IDF (2009) IDF diabetes atlas. 4th Edition, International Diabetes Foundation, Brussels.

[3] UN Resolution 61/225 (2009) Accessed 31 October 2011. http://www.idf.org/diabetesatlas/un-resolution

[4] HSA (2010) Health Statistics Annual, Publication of the Statistics Unit, Ministry of Health and Quality of Life (accessed 20 October 2011).

http://www.gov.mu/portal/site/mohsite

[5] NCD (2009) The mauritius non communicable diseases survey-The trends in diabetes and cardiovascular disease risk in Mauritius. Non-Communicable Diseases, Reduit.

[6] IDF Diabetes Atlas (2002). International Diabetes Foundation.

[7] Dowse, G.K., Gareeboo, H., Zimmet, P.Z., et al. (1990) Abdominal obesity and physical inactivity as risk factors for NIDDM and impaired glucose tolerance in Indian, Creole, and Chinese Mauritians. American Journal of Epidemiology, 118, 673-688.

[8] Shah, P.C. (1987) Diabetes mellitus in and around Bardoli. Journal of the Diabetic Association of India, 27, 11-14.

[9] NSFD. (2007) The national service framework for Diabetes-Mauritius. A ten-year programme. Ministry of Health \& Quality of Life, Accessed 15 December 2012. http://www.gov.mu/portal/sites/diabetes/nsf_diabetes.pdf

[10] Kirigia, J.M., et al. (2009) Economic burden of diabetes mellitus in the WHO African region. BMC International Health and Human Rights, 9, 6. doi:10.1186/1472-698X-9-6

[11] HSA. (2010) Health Statistics Annual, Publication of the Statistics Unit, Ministry of Health and Quality of Life (accessed 25 October 2011) http://www.gov.mu/portal/site/mohsite

[12] Soderberg, S., Dowse, G.K.P. Zimmet, J., et al. (2004) High incidence of type 2 diabetes and increasing conversion rates from impaired fasting glucose and impaired glucose tolerance to diabetes in Mauritius. Journal of Internal Medicine, 256, 37-47.

[13] HSA (2010) Health Statistics Annual, Publication of the Statistics Unit, Ministry of Health and Quality of Life (accessed 12 December 2011). http://www.gov.mu/portal/site/mohsite

[14] Kassean, H. and Narainen, N. (2005). Nurses' perceptions of their role in caring for diabetic patients at the primary care level: A case study from Mauritius. Journal of Health Management, 7, 207-213. doi:10.1177/097206340500700203

[15] Diabetes Mauritius (2006) accessed 14 August 2010 http://www.gov.mu/portal/sites/diabetes/events.htm

[16] Doobaly, P. and Gooneeadry, A (2005) Managing diabetic patients in the community. Unpublished Dissertation.

[17] Salon de al Sante (2011) Plaidoirie pour une population informée Le Mauricien. 28 June 2011.

[18] Ramanah, K. (2006) Strategies for improving diabetic care in Mauritius, Unpublished Dissertation.

[19] Pan X.-R., et al. (1997) Effects of diet and exercise in preventing NIDDM in people with impaired glucose tolerance: The Da Qing IGT and diabetes study. Diabetes Care, 20, 537-544. doi:10.2337/diacare.20.4.537

[20] Diabetes Prevention Program Research Group (2001) Prevention of type 2 diabetes mellitus by changes in lifestyle among subjects with impaired glucose tolerance. The New England Journal of Medicine, 344, 1343-1350. doi:10.1056/NEJM200105033441801

[21] Diabetes Prevention Program Research Group (2002) Reduction in the incidence of type 2 diabetes with life-style intervention or metformin. The New England Journal of Medicine, 346, 393-403.

[22] American Diabetes Association \& National Institute of Diabetes, Digestive and Kidney Diseases (2004) The prevention or delay of type 2 diabetes. Diabetes Care, 27, S47-S54

[23] Eagly, A., et al. (1993) The psychology of attitudes. Harcourt Brace Jovanovich College Publishers, Forth Worth.

[24] National Institute for Health and Clinical Excellence (2011) Behaviour change, Accessed 14 May 2011. http://www.nice.org.uk/PH006

[25] Ewles, L. and Simnett, I. (1996) Promoting health: A practical guide. Balliere Tindall, London.

[26] Wellings, K. and Macdowall, W. (2005) Evaluating mass media approaches to health promotion: A review of methods. Health Education, 100, 23-32.

[27] Winett (1992) North of England study of standards and performance in general practice. Overview of the study. Centre for Health Services Research, Newcastle-Upon Tyne.

[28] Black, E.R., et al. (1994) Innovations in patient care: Changing clinical practice and improving quality. Asso- 
ciation of Health Service Research, 11, 78-79.

[29] Rosenstock, M. (1966) Why people use health services. The Milbank Memorial Fund Quarterly, 44, 94-127.

[30] Becker, M.H. (1974) The health belief model and personal health behaviour. N.J. Charles, London.

[31] Tones, K., Tilford, S. and Robinson, Y. (1990) Health education: Effectiveness and efficiency. Chapman and hall, London.

[32] Beck, V. (2004) Working with daytime and primetime television shows in the United States to promote health. In: Singhal, A., Cody, M.J., Rogers, E.M. and Sabido, M., Eds., Entertainment-education and social change: History, research, and practice. Lawrence Erlbaum and Associates Publishers, Mahwah.

[33] Kreuter, M.W., et al. (2003) Achieving cultural appropriateness in health promotion programs: Targeted and tailored approaches. Health Education \& Behavior, 30, 133146

[34] Bloom, J.R. (1990) The relationship of social support and health. Social Science \& Medicine, 30, 635-637. doi:10.1016/0277-9536(90)90162-L

[35] DeWalt, D.A., et al. (2004) Literacy and health outcomes:
A systematic review of the literature. Journal of General Internal Medicine, 19, 1228-1239. doi:10.1111/j.1525-1497.2004.40153.x

[36] Keller, D.L., et al. (2008) Impact of health literacy on health outcomes in ambulatory care patients: A systematic review. Annals of Pharmacotherapy, 42, 1272-1281. doi:10.1345/aph.1L093

[37] NCD (2004) Non-Communicable Diseases survey. Ministry of Health \& Quality of Life, Reduit.

[38] Glik, D. (2004) Health communication in popular media formats. Medscape Public Health \& Prevention, New York.

[39] Tones, K., Tilford, S. and Robinson, Y. (1990) Health education: Effectiveness and efficiency. Chapman and hall, London.

[40] Nutbeam, D., et al. (1990) Evaluation in Health Education. A review of progress, possibility and problems. Journal of Epidemiology and Community Health, 44, 8389. doi:10.1136/jech.44.2.83

[41] Saunders, R.P., et al. (2005) Developing a process-evaluation plan for assessing health promotion program implementation: A how-to guide. Health Promotion Practice, 6, 134-147. doi:10.1177/1524839904273387 